\title{
O ENSINO JURÍDICO COMO IMPORTANTE FERRAMENTA DE EFETIVAÇÃO DOS DIREITOS FUNDAMENTAIS
}

\author{
Alexandre Torres Petry*
}

\begin{abstract}
RESUMO
O presente estudo analisa o ensino jurídico a partir da perspectiva dos direitos fundamentais. Defende-se, inicialmente, que os direitos fundamentais têm papel central no Direito e, por isso, devem ser fomentados. Após, aborda-se o papel do ensino jurídico, o qual deve estar voltado para a mudança social através de uma formação humanística. Para que isso efetivamente ocorra, analisa-se o atual estágio do ensino jurídico e como deve o mesmo ser reestruturado para atingir seus fins. Ao final, defende-se com veemência que o ensino jurídico é importante ferramenta de efetivação dos direitos fundamentais.
\end{abstract}

PALAVRAS-CHAVE: Ensino Jurídico. Direitos Fundamentais. Formação Humanística.

* Doutorando em Educação na UFRGS. Mestre em Direito pela PUCRS. Especialista em Direito e Economia pela UFRGS. Especialista em Direito do Consumidor e Direitos Fundamentais pela UFRGS. Graduado em Direito pela UFRGS. Membro da Comissão de Ensino Jurídico da OAB/RS. Membro da Comissão Especial de Defesa do Consumidor da OAB/RS. Coordenador e professor do Curso de Capacitação em Direito do Consumidor da Escola Superior de Advocacia da OAB/RS. Coordenador do Grupo de Estudos em Direito do Consumidor da Escola Superior de Advocacia da OAB/RS. Professor em cursos de pós-graduação e graduação. Advogado. 


\title{
THE LEGAL EDUCATION AS AN IMPORTANT TOOL OF EFFECTIVENESS OF FUNDAMENTAL RIGHTS
}

\begin{abstract}
This study analyzes the legal education from the perspective of fundamental rights. It is argued, first, that fundamental rights play a central role in law and therefore should be encouraged. After, it is discussed the role of legal education, which should be facing social change through a humanistic education. For this to occur effectively, analyzes the current state of legal education and how it should be restructured to achieve its purpose. At the end, it is argued vehemently that legal education is important tool of effectiveness of fundamental rights.
\end{abstract}

\section{INTRODUÇÃO}

Os direitos fundamentais são o eixo central do nosso ordenamento jurídico. Irradiam-se para todos os campos do Direito, servindo como vetor para os juristas. Entretanto, uma das grandes questões é como fomentar os direitos fundamentais dando eficácia e eficiência aos mesmos.

Geralmente, os estudos e pesquisas sobre os direitos fundamentais analisam as hipóteses de aplicação e, portanto, partem da realidade e da prática a fim de difundir os direitos fundamentais. Obviamente, essa forma de atuação não está errada, muito pelo contrário, deve continuar ocorrendo e em maior escala.

Entretanto, considerando que a educação tem um potencial transformador incrível na sociedade, estrategicamente, deve-se investir na educação em direitos fundamentais e para os direitos fundamentais em todos os níveis de educação, mas, principalmente, no âmbito superior e nas Faculdades de Direitos.

Uma sociedade calcada nos direitos fundamentais começa pela conscientização das pessoas do que são estes direitos, para que servem e como incidem. De igual forma, esta mesma sociedade precisa ter juristas que acreditem e propaguem os direitos fundamentais, os quais devem ser constantemente incentivados, pesquisados e, principalmente, defendidos, já que não são raros 
os ataques contra os direitos fundamentais, os quais precisam ser preservados, vedando-se retrocessos.

Nesse contexto, o ensino jurídico possui destaque e relevância, considerando que é nas Faculdades de Direito que os direitos fundamentais são estudados com mais afinco. Portanto, é o local ideal para intenso debate, análise, apoio e incentivo. Sem dúvidas, devem as Faculdades de Direito assumir importante papel de desenvolvimento dos direitos fundamentais.

Ocorre que o ensino jurídico no Brasil atingiu um nível preocupante, onde lógicas mercadológicas se impõem a qualquer custo, tornando-se as Faculdades de Direito em verdadeiras empresas que olham para os seus alunos como "consumidores" e respondem aos interesses do mercado, os quais não costumam ser pautados pelos direitos fundamentais. Essa realidade é preocupante, pois baixa em muito o nível e a qualidade de ensino do Direito.

Nessa linha, abordar a questão do ensino jurídico correlacionado com os direitos fundamentais é um desafio necessário e enriquecedor, uma vez que defender os direitos fundamentais deve ser bandeira de todos os juristas, sendo que essa defesa passa pela articulação de um ensino jurídico de qualidade que seja pautado nos verdadeiros interesses da sociedade: a fomentação dos direitos fundamentais e a concretização da cidadania plena.

\section{A CENTRALIDADE DOS DIREITOS FUNDAMENTAIS NO ORDENAMENTO JURÍDICO}

Antes mesmo de defender a centralidade dos direitos fundamentais, ou mesmo os direitos humanos em última instância ${ }^{1}$,

Direitos fundamentais e direitos humanos, embora semelhantes, são distintos. Segundo José Joaquim Gomes Canotilho (2003, p. 393), direitos humanos são direitos válidos para todos os povos e em todos os tempos (representam uma dimensão jusnaturalista-universalista), enquanto os direitos fundamentais são os direitos do homem jurídico-institucionalmente garantidos e limitados no espaço e no tempo. Os direitos humanos possuem sua raiz na própria natureza humana (caráter universal e inviolável), sendo que os direitos fundamentais são os direitos objetivamente reconhecidos (positivados) numa ordem jurídica concreta. 
é importante relembrar que o reconhecimento de que "todos os homens nascem livres e iguais em dignidade e direitos" é uma conquista ainda muito recente na história (COMPARATO, 2015, p. 24). Isso porque, conforme destaca José Reinaldo de Lima Lopes (2014, p. 02), precisamos lançar nosso olhar sobre o passado, ou para buscar a restauração do próprio passado, ou mesmo para perseguir um futuro melhor.

De acordo com o historiador Eric Hobsbawm (1995, p. 562), em fins da década de 1980 e início da década de 1990, sem dúvidas, uma era se encerrou e outra nova muito diferente começou, sendo que ao final da sua obra o autor ainda conclui que se a sociedade quer ter um futuro reconhecível, não pode ser pelo prolongamento do passado, pois se tentarmos construir o novo século com base no passado, certamente fracassaremos.

Este novo século precisa ser melhor que os anteriores e, assim, estar alicerçado, no plano internacional, sobre os direitos humanos e, no plano nacional, sobre os direitos fundamentais, os quais são reconhecidos pela nossa Constituição como cláusulas pétreas e, mais do que isso, dotados de centralidade e eficácia.

Todas as normas constitucionais são dotadas de um mínimo de eficácia e, no caso dos direitos fundamentais, com base no art. 5ํㅡ, § $1^{\text {o }}$ da Constituição Federal, cabe aos poderes públicos o dever de extrair das normas que o consagram a maior eficácia possível, possuindo os direitos fundamentais efeitos reforçados em relação a todas as demais normas constitucionais (SARLET, 2009, p. 271).

Logo, sobre os direitos fundamentais impera a aplicabilidade imediata e eficácia plena, devendo os direitos fundamentais ser reais e efetivos, assumido o Estado a tarefa constitucional de maximizar a eficácia dos direitos fundamentais, pois, afinal, nas palavras de Paulo Caliendo (2009, p. 19), "as normas constitucionais são comandos normativos e não peças de literatura". ${ }^{2}$

2 Ronald Dworkin utiliza a expressão "levando os direitos a sério", questionando se os mesmos devem ser levados à sério, respondendo sua própria pergunta de forma afirmativa, pois "a instituição dos direitos é crucial, pois representa a promessa da maioria às minorias de que sua dignidade e igualdade serão respeitadas (DWORKIN, 2002, p. 314). 
Dessa forma, os direitos fundamentais não são mera expectativa, retórica ou "faz de conta", são direitos dotados de eficácia e que possuem relevante papel na sociedade. Além disso, conforme expõe Eugênio Facchini Neto (2007, p. 161), atualmente, o Direito possui uma função diretiva da mudança social, sendo que esta função deve ser desempenhada por aqueles agentes que acreditam ser sempre possível contribuir para a melhoria das relações sociais. 0 referido autor ressalta inclusive que o Poder Judiciário é imprescindível para a saudável convivência social na medida em que deve zelar pelos direitos fundamentais, arrematando, por exemplo, com a seguinte visão do Poder Judiciário e do juiz contemporâneo:

\begin{abstract}
Mas também o Judiciário se faz cada vez mais imprescindível para a saudável convivência social, zelando para que sejam respeitados os direitos fundamentais dos cidadãos, não só pelo Estado, mas também pelos demais concidadãos. (...)

E, sobretudo, exige um Juiz comprometido com o valor mor dos ordenamentos jurídicos contemporâneos, qual seja, a dignidade do ser humano, com direito a um mínimo existencial e ao pleno respeito as seus direitos fundamentais.
\end{abstract}

Segundo Virgílio Afonso da Silva (2011, p. 172), "proteger o conteúdo essencial de um direito fundamental significa proibir restrições à eficácia desse direito que o tornem sem significado para todos os indivíduos ou para boa parte deles". Diante disso, considerando que os direitos fundamentais possuem centralidade no nosso ordenamento jurídico, possuindo a dignidade da pessoa humana importante função de referencial vinculante para o processo decisório no meio social (SARLET, 2011, p. 172), é dever de todo o jurista propagar a aplicação dos direitos fundamentais.

Portanto, importa agora analisar como se dá atualmente a formação dos nossos juristas, ou seja, se os mesmos têm acesso à educação jurídica enraizada em bases humanistas respaldadas pelos direitos fundamentais, debruçando-se, assim, sobre 
as características atuais do ensino jurídico, pois, sem dúvidas, há relação imediata entre a formação acadêmica de um jurista (podendo ele ser advogado, juiz, promotor, defensor público, delegado, enfim, qualquer uma das carreiras jurídicas) e a forma da sua atuação profissional.

\section{O PAPEL DO ENSINO JURÍDICO: FORMAÇÃO HUMANÍSTICA}

A primeira pergunta a ser feita é: qual a função do ensino jurídico contemporâneo? A doutrina traz uma série de respostas, mas todas convergindo para uma realidade: mudança social.

Sérgio Rodrigo Martínez (2012, p. 43) destaca a necessidade de implantação de responsabilidade social no ensino jurídico, "sob pena da perpetuação jurídica das desigualdades e exclusões sociais observadas no cotidiano nacional". Já André Copetti e José Luis Bolzan de Morais (2007, p. 17) ressaltam que o ensino jurídico deve estar compromissado "com a liberdade, com a justiça social, com a solidariedade, com a erradicação da pobreza e da marginalização e com a redução das desigualdades sociais".

No mesmo sentido Alexandra Silva Scoz (2012, p. 138) traz que cabe ao ensino jurídico combater as desigualdades e "(re) criar fontes, pluralizar vivências ao incremento de um processo de evolução e integração de conhecimento e culturas". André Luiz Lopes dos Santos (2002, p. 218) caracteriza o ensino jurídico como "instrumento de fomento e sedimentação da uma cultura democrática". Numa visão mais abrangente, Maria Cecilia Lorea Leite (2014, p. 16) aponta o ensino jurídico como uma perspectiva que "possa superar a distância dos problemas da realidade social, dinâmica e complexa, proporcionar uma formação profissional qualificada, que contribua para uma ordem social mais justa e a ampliação do acesso à justiça”.

Já Maria Garcia (2013, p. 361) conclui que o ensino jurídico tem que ter um sentido social e preparar as pessoas para o 
exercício da cidadania plena e completa, além da qualificar para o trabalho. Ademais, destaca a autora que o ensino jurídico tem que investir na democracia, até porque a educação é a base da democracia.

Deste modo, o ensino jurídico está ligado à ideia de mudança social, cidadania e democracia, sendo que o seu vetor são os direitos humanos, exigindo-se, para tanto, uma formação humanística.

A formação humanística é muito mais que uma missão, já que dever legal. Isso porque a Constituição Federal traz já no seu art. 205 que a educação visa o pleno desenvolvimento da pessoa, estabelecendo, em primeiro lugar o exercício da cidadania como foco e, após, a qualificação para o trabalho. Prosseguindo na análise da carta magna, o art. 214, no seu inciso V, estabelece que a educação deve promover a formação humanística.

Segundo Maria Garcia (2011, p. 286), o intérprete, necessariamente, deve deter-se na expressão "promoção humanista" com o fim de alcançar um sentido humanístico ao ensino. A ideia humanista também aparece no art. 1ํㅡㄹ inciso III da Constituição, que estabelece a dignidade da pessoa humana. Portanto, nitidamente a Constituição Federal abarcou o sentido de humanismo, que no século XXI apresenta a vertente da universalidade dos direitos humanos.

Essa primeira leitura do texto constitucional é essencial, pois apresenta a vontade do legislador e o compromisso do Estado com os direitos humanos, sendo que a formação humanística deve ser fomentada através da educação. Essa linha humanista está de acordo com o pensamento de Paulo Freire (2011, p. 110), que sustenta a "impossibilidade da neutralidade da educação". A educação deve ter um papel transformador, deve mudar e a mudança precisa se dar a partir da formação humanística, aliás, preceito constitucional.

Em termos de ensino jurídico, a legislação que regulamentava os cursos de Direito era a portaria no 1.886 de 30 de dezembro 
de 1994, a qual fixava as diretrizes curriculares e o conteúdo mínimo do ensino jurídico. Nessa norma não existia qualquer referência ou "preocupação" com a formação humanística. Pelo contrário, a fixação do conteúdo mínimo, prevista no art. 6ํㅜㄹ, sequer fazia referência aos direitos humanos.

Porém, passada quase uma década, no ano de 2004 sobreveio a Resolução CNE/CES no 9, de 29 de setembro de 2004, a qual institui novas Diretrizes Curriculares Nacionais do Curso de Graduação em Direito, revogando a anterior portaria no 1.886 . Sem dúvidas, essa nova legislação representou avanço, pois estabeleceu para os cursos jurídicos o foco na formação humanística e com autonomia do educando, conforme disposto no art. $3^{0}{ }^{\circ}$.

Dessa forma, é evidente que este novo marco trouxe a preocupação com a formação humanística aliada a uma postura reflexiva e com capacidade para uma aprendizagem autônoma. Logo, indubitavelmente, foi um grande avanço, ainda que possa ser criticada pelo fato de novamente não ter estabelecido um foco específico nos direitos humanos, disciplina sequer citada nos eixos de formação previstos no art. 5ํ da referida norma, a

3 Art. 6o 0 conteúdo mínimo do curso jurídico, além do estágio, compreenderá as seguintes matérias que podem estar contidas em uma ou mais disciplinas do currículo pleno de cada curso:

I - Fundamentais: Introdução ao Direito, Filosofia (geral e jurídica, ética geral e profissional), Sociologia (geral e jurídica), Economia e Ciência Política (com teoria do Estado);

II - Profissionalizantes Direito Constitucional, Direito Civil, Direito Administrativo, Direito Tributário, Direito Penal, Direito Processual Civil, Direito Processual Penal, Direito do Trabalho, Direito Comercial e Direito Internacional.

4 Art. $3^{3}$. 0 curso de graduação em Direito deverá assegurar, no perfil do graduando, sólida formação geral, humanística e axiológica, capacidade de análise, domínio de conceitos e da terminologia jurídica, adequada argumentação, interpretação e valorização dos fenômenos jurídicos e sociais, aliada a uma postura reflexiva e de visão crítica que fomente a capacidade e a aptidão para a aprendizagem autônoma e dinâmica, indispensável ao exercício da Ciência do Direito, da prestação da justiça e do desenvolvimento da cidadania. 
qual teve uma preocupação de fato muito maior com a formação para as exigências do mercado.

Destaca-se que essa crítica quanto à ausência de foco na educação em direitos humanos é sempre oportuna, uma vez que, segundo Anna Candida da Cunha Ferraz (2013, p. 100) "a educação em direitos humanos, sendo pressuposto essencial para o exercício da cidadania plena, deverá constar das grades curriculares de ensino no Brasil”. Porém, não deveria ser como um a disciplina opcional ou com pouca relevância no curso. Defende-se a sua centralidade!

Nesse sentido, cita-se a Resolução no 1 , de 30 de maio de 2012, do Conselho Nacional de Educação, que estabelece as diretrizes nacionais para a educação em direitos humanos determinado que as Instituições de Ensino Superior deverão efetivar a educação em direitos humanos com o foco na mudança e transformação social, tanto é que a educação em direitos humanos deve fazer parte dos Programas Pedagógicos dos Cursos, bem como todos os profissionais da educação precisam ter formação contínua em direitos humanos.

Portanto, essa resolução emitida pelo órgão máximo da Educação no Brasil (já que ligado ao Ministério da Educação), corrobora assertiva que os direitos humanos possuem centralidade na educação, o que se dá em todos os níveis, mas, principalmente, no curso do Direito dada as suas peculiaridades, onde essa centralidade deve ser reforçada.

Nessa linha, o ensino jurídico tem que contemplar uma visão humanista e, consequentemente, deve ser focado nos direitos fundamentais, já que desdobramento dessa linha humanista. 0 grande problema é que o ensino jurídico, infelizmente, tem-se distanciado do seu foco e, atendendo exigências do mercado, num nítido processo de mercantilização (tanto instituições público como privadas), sofre um processo de "adaptação" às exigências do capital. Essa realidade é muito séria, preocupante e exige profunda reflexão. 


\section{ENSINO JURÍDICO EM CRISE?}

Estaria o ensino jurídico em crise? Este questionamento é muito importante e, inclusive, põe em xeque a concepção ideológica de quem responde a questão, pois não há como ficar indiferente aos rumos que o ensino jurídico trilhou, principalmente, nas últimas duas décadas.

Segundo Paulo Freire não há como ficar indiferente ante os problemas que se apresentam ao educador. Isso porque, uma das coisas que se espera da educação é que ela melhore a sociedade, o que pode ser alcançado quando a educação é feita com uma orientação crítica, libertadora e dialógica (FLECHA, 2001, p. 205). Além disso, a educação é um compromisso de todos em construir uma sociedade livre, em que a pessoa tenha um desenvolvimento integral para que possa ser agente transformador da sociedade em que vive (ARAUJO, 2010, p. 26).

O ensino jurídico está em crise sim, sendo que as perspectivas são negativas. Vários são os motivos dessa crise, que enfraquecem a qualidade do ensino, promovendo a formação de juristas, na média, cada vez mais incapazes, o que, sem dúvidas, é ruim para a sociedade de uma forma geral, já que o exercício da justiça fica comprometido como um todo.

Vivemos a era da massificação do ensino jurídico no Brasil, que é um fenômeno negativo. Sobre essa massificação ${ }^{5}$, cabe citar as palavras de João Maurício Adeodato (2013, p. 566):

Sobre a existência do fenômeno não há qualquer dúvida, com dados que beiram o absurdo e que seriam cômicos se não fossem trágicos: há hoje (novembro de 2011) 1.210 cursos de direito no Brasil, e é matematicamente impossível que essa massa de alunos venha algum dia a trabalhar em profissões jurídicas. 0 debate importante é entender como isto está acontecendo, a quem aproveita e o que fazer para proteger a qualidade da prestação de serviços jurídicos no país.

João Maurício Adeodato ainda apresenta outros dados quanto ao número de cursos jurídicos, referindo na página 568 o seguinte: "Em detalhes, pensando no número dos cursos de direito existentes hoje nos países ditos emergentes (os BRICs), o Brasil tem 1.210, a Índia, 1.136, a China, 987, e a Rússia, 468." 
A problemática do ensino jurídico não é recente como alerta Fernanda Arruda Dutra (2010, p. 106), destacando que ainda em 1907 foi publicada a obra denominada de "A reforma do Ensino Jurídico do Brasil", de Aureliano Leal, que desde então já apresentava preocupação e uma visão crítica com os métodos educacionais da época. Ademais, em 1958 a Ordem dos Advogados do Brasil já realizava conferência para refletir sobre o tema. A referida autora, que apresenta a evolução histórica do ensino jurídico até os dias atuais, conclui que temos um "modelo de ensino jurídico que pouco mudou desde a fundação dos primeiros cursos jurídicos no país. Enquanto a sociedade, nesse mesmo período, passou por transformações radicais".

Não se está aqui defendendo que a educação jurídica no Brasil sempre foi deficitária, pelo contrário. Isso porque, não se pode negar a absoluta importância da educação jurídica na evolução do país, uma vez que os cursos jurídicos fundados a partir de 1827 foram os principais responsáveis pela constituição de recursos humanos empregados em diversas áreas do Estado desde o século XIX (BENTO; MACHADO, 2013, p. 209).

Porém, é fato que apesar das inovações legislativas, o ensino jurídico ainda está ligado aos moldes tradicionais, inspirados em modelos ultrapassados ante as profundas transformações sociais, políticas, culturais, econômicas e, principalmente, jurídicas. A sociedade moderna possui novas expectativas, novos problemas, novas demandas que, sem dúvidas, não podem ser resolvidas pelas soluções do passado (DUARTE; DUARTE, 2012, p. 172).

Na mesma linha se posiciona Fabiano Lepre Marques (2011, p. 196), que assim se manifesta sobre o atual estágio do ensino jurídico no Brasil:

O atual ensino jurídico tornou-se um processo de repetição de conteúdos já pré-determinados e codificados, que baseados em uma interpretação meramente legalista, traduzem verdades absolutas e inquestionáveis. Em face dessa problemática, constata-se que o ensino jurídico baseado na sim- 
ples leitura de textos de lei não capacita seus operadores a enfrentarem os novos problemas sociais, constituindo, dessa forma, uma verdadeira farsa na qual o professor finge que ensina e os alunos representam que aprendem.

Deve-se ressaltar também que a crise do ensino jurídico está atrelada ao contexto social, econômico, político e cultural da sociedade moderna brasileira. Na verdade, pode-se afirmar que a crise do ensine jurídico está relacionada com a crise do próprio Direito, pois ela decorre das profundas e rápidas transformações sociais que a sociedade sofreu, principalmente, nas últimas duas décadas, razão pela qual deve ser proposta uma mudança no método o ensino do Direito, o que acabará por contribuir para a própria evolução do Direito (MOTA, 2011, p. 353).

É tamanha a crítica ao atual nível em que se encontra o ensino jurídico que, segundo Plínio Antônio Britto Gentil (2013, p. 420), chega-se ao extremo de afirmar que "já está se tornando usual comparar os conteúdos do ensino de direito a um prato de fast-food". O referido autor vai além e, na sua visão crítica, afirma que essa formação superficial que torna o futuro jurista incapaz de resolver problemas complexos é oriundo das exigências do mercado, de uma sociedade capitalista que mercantiliza o ensino.

Essa mercantilização do ensino jurídico é um fenômeno da sociedade moderna ainda pouco estudado, o qual é um grande desafio aos educadores ligados ao Direito, pois está entre as principais causas da crise do ensino jurídico. Prova disso é que ocorreu uma assustadora proliferação das Faculdades de Direito no Brasil nas últimas décadas. Tanto é verdadeira essa alegação que o Brasil é um dos países que mais possui Faculdades de Direito no mundo. Atualmente, o país conta com cerca de 1300 cursos, sendo que no início da década de 1990 eram apenas $200 .^{6}$

6 Segundo informações prestadas em 22 de janeiro de 2014 pelo Presidente da Ordem dos Advogados do Brasil. Disponível em http://www.oab.org.br/ noticia/26589/presidente-da-oab-fala-sobre-ensino-juridico-ao-congresso-em-foco?argumentoPesquisa=formsof(inflectional, "faculdades") and formsof(inflectional, "direito"). Acesso em 18 de maio de 2015. 
Fenômeno parecido ocorre com as especializações em direito e MBA, cursos estes com pouco controle, fato reconhecido pelo próprio MEC. 7

Segundo Eid Badr (2011, p. 81), "a mercantilização do ensino acaba por levar a desumanização do professor e do aluno, e à coisificação da educação".

Porém, parte-se do princípio que este fenômeno não é exclusivo ou isolado das Faculdades de Direito, mas sim ocorre no âmbito da Universidade como um todo, no qual estão inseridas as Faculdades de Direito, não podendo a análise ser descolada do contexto universitário, sob pena de minimização do problema.

Entretanto, reconhecer a crise do ensino jurídico, a qual ocorre principalmente pela mercantilização das Faculdades de Direito, é o primeiro passo para a busca da solução. 0 segundo é tratar do problema, defendendo-se vigorosamente uma formação humanística dos juristas, que precisam ter acesso a um ensino jurídico com foco na defesa e concretização dos direitos fundamentais.

\section{POR UM ENSINO JURÍDICO VOLTADO PARA A DEFE- SA E CONCRETIZAÇÃO DOS DIREITOS FUNDAMENTAIS}

0 ensino jurídico precisa possuir uma autêntica função social, sendo que a visão ultrapassada do conhecimento das leis, doutrina e jurisprudência não é mais suficiente, já que superada. O ensino jurídico deve estar voltado para a interferência na sociedade e, com isso, promover a necessária mudança social em busca de justiça e harmonia. A promoção dos direitos fundamentais começa nas Faculdades de Direito, sendo que a partir de então deve se espalhar por toda a sociedade, a qual deve ter ciência e exercer os seus direitos, principalmente, os fundamentais, pois somente dessa forma teremos uma efetiva e plena cidadania.

Segundo notícia veiculada em abril de 2014. Disponível em http://g1.globo. com/bom-dia-brasil/noticia/2014/04/mec-admite-que-nao-tem-controlesobre-pos-graduacao-e-mba.html. Acesso em 18 de maio de 2015. 
Com a ciência e promoção dos direitos é que teremos condições de alcançar uma verdadeira democracia, conforme destacam Elaine Cristina da Silva Ruellas e Wilges Ariana Bruscato (2011, p. 38):

\begin{abstract}
Assim, a autêntica democracia não se resume à representação, mas à participação ativa da comunidade popular. Para isso faz-se necessário a conscientização dos direitos, bem como os instrumentos para sua efetivação e proteção. Torna-se evidente a correlação e interdependência das questões de direitos fundamentais, democracia e cidadania, para a concretização de um legítimo Estado Democrático de Direito, com possibilidade de redução das desigualdades.
\end{abstract}

Nessa linha, refletindo sobre os operadores de direitos que necessitamos atualmente, bem como sobre as necessárias mudanças do ensino jurídico, as quais precisam estar pautadas na mudança social, Antônio Alberto Machado se posiciona da seguinte forma (2009, p. 177):

Logo, se há uma missão constitucional de defesa legítima da 'ordem jurídica democrática' pelos operadores do direito, a alternativa que resta aos integrantes das carreiras jurídicas é, segundo pensamos, a de atuar mais no sentido do aprofundamento da democracia no âmbito das classes populares, lutando pela distribuição igualitária dos direitos fundamentais da pessoa humana e pela radicalização da cidadania, do que, propriamente, atuar apenas na aplicação e fiscalização formalista de uma legalidade no mais das vezes bloqueia a inclusão das massas populares, limitando a distribuição democrática da justiça social em nome da lei e da ordem.

Para repensar o Direito, antes, impõe-se repensar o ensino do Direito. Sem uma modificação de fato no ensino jurídico, não teremos uma mudança efetiva no meio jurídico em que atuamos. Se a sociedade precisa ser guiada pelos direitos fundamentais, o ensino jurídico também. Nesse sentido, importante são as palavras de Eduardo C. B. Bittar (2006, p. 11): 
Sem dúvida alguma, se se tiver que pensar na modificação das práticas jurídicas, no aperfeiçoamento do ordenamento jurídico brasileiro, na modificação da cultura das instituições, ter-se-á que partir pela reforma do próprio modus pelo qual o Direito é ensinado, e da inter-ação entre teoria e prática, entre escola e profissão, entre reflexão acadêmica e implementação de reformas institucionais, pode-se até mesmo entrever, haverá de surgir a necessária e indispensável simbiose para a re-adequação do ensino jurídico brasileiro.

Considerando que os direitos humanos têm um caráter universal, bem como que a proteção internacional é mais difícil do que a proteção no interior de um Estado (BOBBIO, 1992, p. 63), são os direitos fundamentais que acabam assumindo relevância, já que dotados de eficácia direta (exigíveis). Nessa linha, o ensino jurídico tem que estar voltado para uma visão social, a qual passa pelo fomento, promoção, defesa e busca de efetivação dos direitos fundamentais.

Se precisamos reconstruir o direito nacional, como destaca Antonio Carlos Wolkmer (2015, p. 167) ao afirmar que necessitamos de novos juristas "comprometidos com a superação dos velhos paradigmas e com as transformações das instituições arcaicas, elitistas e não democráticas", isso somente se dará pela ruptura de paradigmas do ensino jurídico, o qual tem que reconhecer a centralidade dos direitos humanos, abarcando uma formação humanística que busque expandir na sociedade a cultura dos direitos fundamentais.

\section{CONCLUSÕES}

Os direitos fundamentais são a base do nosso ordenamento jurídico. Portanto, precisam ser fomentados e expandidos o máximo possível. Uma sociedade ciente, que respeite e exercite os direitos fundamentais, sem dúvidas, será uma sociedade democrática e com cidadania efetiva e plena.

Porém, apesar arcabouço legal em torno dos direitos fundamentais, os mesmos ainda não possuem de fato a primordial 
relevância que foi atribuída no ordenamento jurídico. Interferir e alterar essa realidade social passa, necessariamente, por uma mudança de paradigma no ensino jurídico, o qual está em crise e clama por transformações, o que começará pela implementação efetiva de uma formação humanística e que seja voltada para o atual contexto social, o qual revela inúmeras desigualdades que precisam ser combatidas.

Aperfeiçoar o ordenamento jurídico para o foco na concretização e efetivação dos direitos fundamentais perpassa, necessariamente, pela melhoria do ensino jurídico, o qual deve adotar uma formação humanística, que valorize os direitos humanos, defenda e estimule os direitos fundamentais, bem como estimule a verdadeira cidadania participativa, o que, em última análise, trará justiça acompanhada de mudança social.

Logo, o momento é de mudança no ensino jurídico, que precisa atender a sua função social, ou seja, formar juristas cientes a aptos da sua relevância social, que defendam e busquem efetivar sempre os direitos fundamentais para a formação de uma sociedade mais justa, harmônica e solidária.

\section{RERÊNCIAS}

ADEODATO, João Maurício. A OAB e a massificação do ensino jurídico. In: SILVEIRA; Vladimir Oliveira da; SANCHES, Samyra Haydêe Dal Farra Naspolini; COUTO, Mônica Bonetti (Orgs.). Educação jurídica. São Paulo: Saraiva, 2013.

ARAUJO, Ana Laura Vallarelli Gutierres. Educações; prática de liberdade e da responsabilidade. Revista de Direito Educacional, São Paulo, n. 2, p. 13-26, jul./dez. 2010.

BADR, Eid. Curso de direito educacional: o ensino superior brasileiro. Curitiba: CRV, 2011.

BENTO, Flávio; MACHADO, Edinilson Donisete. Educação jurídica e função educacional. In: SILVEIRA; Vladimir Oliveira da; SANCHES, Samyra Haydêe Dal Farra Naspolini; COUTO, Mônica Bonetti (Orgs.). Educação jurídica. São Paulo: Saraiva, 2013. 
BITTAR, Eduardo C. B. Estudos sobre ensino jurídico: pesquisa, metodologia, diálogo e cidadania. 2. ed. São Paulo: Atlas, 2006.

BOBBIO, Norberto. A era dos direitos. Tradução Carlos Nelson Coutinho. Rio de Janeiro: Campus, 1992.

BRUSCATO, Wilges Ariana. RUELLAS, Elaine Cristina da Silva. Direitos fundamentais: desconhecimento e interesse. Revista de Direito Educacional, São Paulo, n. 3, p. 21-40, jan./jun. 2011.

CANOTILHO, José Joaquim Gomes. Direito constitucional e teoria da constituição. 7. ed. Coimbra: Almedina, 2003.

COMPARATO, Fábio Konder. A afirmação histórica dos direitos humanos. 9. ed. São Paulo: Saraiva, 2015.

DWORKIN, Ronald. Levando os direitos a sério. Tradução Nelson Boeira. São Paulo: Martins Fontes, 2002.

DUARTE, Maurizete Pimentel Loureiro; DUARTE, Gerson Constância. A pedagogia como instrumento utilizado na formação dos alunos no curso de direito. Revista de Direito Educacional, São Paulo, n. 6, p. 163-176, jul./dez. 2012.

DUTRA, Fernanda Arruda. 0 problema do ensino jurídico no Brasil breves reflexões. In: TRINDADE, André (Coord.). Direito educacional: sob uma ótica sistêmica. Curitiba: Juruá, 2010.

FACCHINI NETO, Eugênio. 0 judiciário no mundo contemporâneo. Revista da AJURIS: Associação dos Juízes do Rio Grande do Sul, Porto Alegre, n.108, p. 139-165, dez. 2007.

FERRAZ, Anna Candida da Cunha. Educação em direitos humanos: pressupostos para o exercício da cidadania. In: SILVEIRA; Vladimir Oliveira da; SANCHES, Samyra Haydêe Dal Farra Naspolini; COUTO, Mônica Bonetti (Orgs.). Educação jurídica. São Paulo: Saraiva, 2013, p. 87-101.

FLECHA, Ramón. Por que Paulo é o principal pedagogo na atual sociedade da informação? In: FREIRE, Ana Maria Araújo (Org.). A pedagogia da libertação em Paulo Freire. São Paulo: Editora UNESP, 2001.

FREIRE, Paulo. Pedagogia da autonomia: saberes necessários à prática educativa. São Paulo: Paz e Terra, 2011.

GARCIA, Maria. Art. 205 da CF: o pleno desenvolvimento da pessoa e a educação integrativa. Revista de Direito Educacional, São Paulo, n. 4, p. 285-293, jul./dez. 2011. 
. 0 direito e o ensino do direito. Educação e democracia: "a escola da liberdade" (Sampaio Dória). In: SILVEIRA; Vladimir Oliveira da; SANCHES, Samyra Haydêe Dal Farra Naspolini; COUTO, Mônica Bonetti (Orgs.). Educação jurídica. São Paulo: Saraiva, 2013, p. 357-368.

GENTIL, Plínio Antônio Britto. A (in)eficiência da justiça e a preparação do bacharel. In: SILVEIRA; Vladimir Oliveira da; SANCHES, Samyra Haydêe Dal Farra Naspolini; COUTO, Mônica Bonetti (Orgs.). Educação jurídica. São Paulo: Saraiva, 2013.

HOBSBAWM, Eric J. Era dos Extremos: o breve século XX: 1914-1991. Tradução Marcos Santarrita. São Paulo: Companhia das Letras, 1995.

LEITE, Maria Cecilia Lorea. Imagens da justiça, currículo e pedagogia jurídica. In: LEITE, Maria Cecilia Lorea (org.). Imagens da justiça, currículo e educação jurídica. Porto Alegre: Sulina, 2014, p. 15-57.

LOPES, José Reinaldo de Lima. O direito na história: lições introdutórias. 5. ed. São Paulo: Atlas, 2014.

MACHADO, Antônio Alberto. Ensino jurídico e mudança social. São Paulo: Atlas, 2012.

MARQUES, Fabiano Lepre. Ensino jurídico: o embate entre a formação docente e o pacto de mediocridade. Revista de Direito Educacional, São Paulo, n. 3, p. 189-207, jan./jun. 2011.

MARTÍNEZ, Sérgio Rodrigo. Pedagogia jurídica. Curitiba: Juruá, 2012.

MOTA, Sergio Ricardo Ferreira. Metodologia do ensino crítico do Direito Tributário no Brasil: uma proposta para a superação da crise do ensino jurídico. Revista de Direito Educacional, São Paulo, n. 4, p. 337-360, jul./ dez. 2011.

SANTOS, André Leonardo Copetti; MORAIS, José Luis Bolzan de. $O$ ensino jurídico e a formação do Bacharel em Direito: diretrizes político-pedagógicas do curso de Direito da UNISINOS. Porto Alegre: Livraria do Advogado, 2007.

SANTOS, André Luiz Lopes dos. Ensino Jurídico: uma abordagem político-educacional. Campinas; Edicamp, 2002.

SARLET, Ingo Wolfgang. A eficácia dos direitos fundamentais: uma teoria geral dos direitos fundamentais perspectiva constitucional. 10. ed. Porto Alegre: Livraria do Advogado, 2009. 
SCOZ, Alexandra Silva. Ensino jurídico de graduação brasileiro: ensaio sobre a produção de direito na pós-modernidade. Rio de Janeiro: Lumen Juris, 2012.

SILVA, Vírgilio Afonso da. Direitos Fundamentais: conteúdo essencial, restrições e eficácia. 2. ed. São Paulo: Malheiros, 2011.

SILVEIRA, Paulo Antônio Caliendo Velloso da. Direito tributário e análise econômica do direito. Rio de Janeiro: Elsevier, 2009.

WOLKMER, Antonio Carlos. História do Direito no Brasil. 8. ed. Rio de Janeiro: Forense, 2015. 